\title{
Implementasi Algoritma Discrete Furier Transform untuk Karakterisasi Nada dari Huruf Vokal
}

\author{
Amirin Kusmiran \\ Fakultas Teknologi Pertambangan Universitas Teknologi Sumbawa \\ amirin19@gmail.com
}

\begin{abstract}
Abstrak
Sinyal atau gelombang merupakan salah satu phenomena fisik yang telah banyak diaplikasi dibidang sains dan teknologi untuk mengkarakterisasi suatu bahan, seperti retakan dan kandungan dari material, dan nada. Sifat fisik yang digunakan untuk mengkarakterisasi bahan adalah frekuensi. Frekuensi yang dihasilkan oleh manusia berberda-berbeda dikarenakan tekanan, pita suara juga berbeda-beda. Penekanan suara dapat dikarakterisasi dalam domain waktu, sedangkan frekuensinya dapat dikarakterisasi dalam domain frekuensi. Untuk mengkaraterisasi, nada tersebut direkam dengan menggunakan microphone. Hasil rekaman tersebut akan tersimpan di dalam soundcard yang terintegrasi dengan personal computer (PC), kemudian dianalisis dengan menggunakan algoritma yang diimplementasi kedalam matlab. Algortima tersebut adalah algoritma recording dan discrete Fourier transform (DFT). Windows leakage dapat diminimalisasi menggunakan algoritma Blackmann dan Barthannwin modified. Frekuensi ,dan amplitudo yang dihasilkan oleh nada darihuruf vokala dalahnada $\boldsymbol{I}$ adalah 190 $\mathrm{Hz}$ dengan amplitudo 0,14 dB, nada $\boldsymbol{o}$ adalah $580 \mathrm{~Hz}$ dengan amplitudo 0,1 dB, nada $\boldsymbol{u}$ adalah $210 \mathrm{~Hz}$ dengan amplitudo 0,15 dB, nada $\boldsymbol{e}$ adalah $200 \mathrm{~Hz}$ dengan amplitudo 0,13 dB, dan nada aadalah $310 \mathrm{~Hz}$ dengan 0,1 dB.Noise yang dihasilkan oleh nada $\boldsymbol{o}$ pada saat pengambilan data disebabkan oleh perangkat personal computer (PC).
\end{abstract}

Kata kunci: Discrete Fourier transform, algoritma Blackmann dan Barthannwin modified

\subsection{Pendahuluan}

Sinyal memegang peranan penting untuk menganalisis suara. Suara yang dihasilkan akan berbeda-beda sesuai dengan sumber suara, terutama pada suara manusia. Perbedaan ini disebabkan oleh perbedaan frekuensi karakteristik, frekuensi alamiah, yang dihasilkan oleh pita suara. Nada yang dihasilkan oleh pita suara tersebut dapat dianalisis dan diestimasi dengan menggunakan pitch detection algorithma (PDA) sebagaimana dinyatakan oleh Gerhard, D., 2003. Analisis sinyal dapat dilakukan dalam domain waktu, dan domain frekuensi.

Pada domain waktu sinyal dapat dianalisis dengan menggunakan time event rate dan autocorrelation, sedangkan pada domain frekuensi sinyal dapat dianalisis dengan menggunakan transformasi Fourier, short Fourier transfoms (STFT), dan wavelet. Untuk sinyal yang bersifat periodik seperti nada manusia dapat lebih mudah dianalisis dengan menggunakan discrete fourier transform (DFT). Selain untuk menganalisis suara, metode ini dapat digunakan untuk menganalisa kegegalan dari suatu material sebagaimana yang telah dilakukan oleh Niederwimmer, K., dkk., 2015.

Estrada, R., 2008 menggunakan transformasi Fourier untuk mengolah sinyal suara. berdasarkan kajian yang telah dilakukan oleh Estrada, R., 2008, penelitian ini berfokus untuk mengkarakterisasi sinyal suara atau nada yang dihasilkan oleh pita suara. penelitian ini menggunakan perangakat keras seperti sound card dan microphone, dan perangat lunak, seperti matlab R2014A. Karakterisasi nada dapat dilakukan dalam domain waktu dan frekuensi. Karakterisasi dalam domain waktu dapat berupa amplitudo nada, sedangkan dalam domain frekuensi dapat mengkarakterisasi frekuensi dari nada.

\subsection{Tinjauan Pustaka}


Suara yang dihasilkan oleh manusia merupakan kombinasi dari paru, glottis (dengan vocal cords), dan articulation tract (mulut dan rongga hidung) sebagaimana tampak pada Gambar 1.

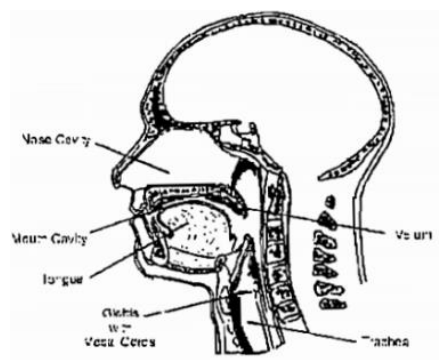

Gambar 1. Organ pembangkit nada.

Sinyal yang keluar dari rongga mulut akan merambat diudara. Pola rambatan dari gelombang suara berulang-berulang dalam interval tertentu secara periodik. Sehingga dapat dikatakan bahwa sinyal yang dihasilkan oleh pita suara merupakan sinyal yang seragam seperti yang tampak pada Gambar 2.

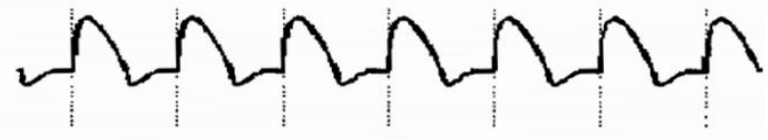

Gambar 2. Impuls pada sinyal wicara (Estrada,R., 2008)

Sinyal atau nada tersebut akan dianalisis dengan menggunakan algoritma discrete Fourier Transform (DFT). DFT merupakan salah satu metode yang digunakan untuk analisis spektrum gelombang yang seragam atau sinusoidal, dan berfungsi untuk mentrasformasikan sinyal dalam domain waktu ke domain frekuensi sebagaimana diilustrasikan oleh Gambar 5 .Persamaan yang digunakan untuk mentransformasi domain waktu ke frekuensi diperlihatkan oleh Persamaan (1) (Gilat, A., dan Subramanian, V., 2013).

$$
F_{k}=\sum_{j=1}^{N} f\left(t_{j}\right) e^{\frac{2 \pi(k-1)(j-1)}{N}}
$$

dimana $N$ adalah jumlah titik sampling, $f(t)$ adalah data dalam domain waktu yang merupakan inversi dari DFT. Jika Sinyal yang dihasilkan oleh pembangkit tidak sinusoidal (window leakege), Algoritma Blackmman dan Bartlet-Hann, Gambar 3 dan 4, dapat digunakan untuk mengurangai window leakage (Oppenheim, dkk., 1999).
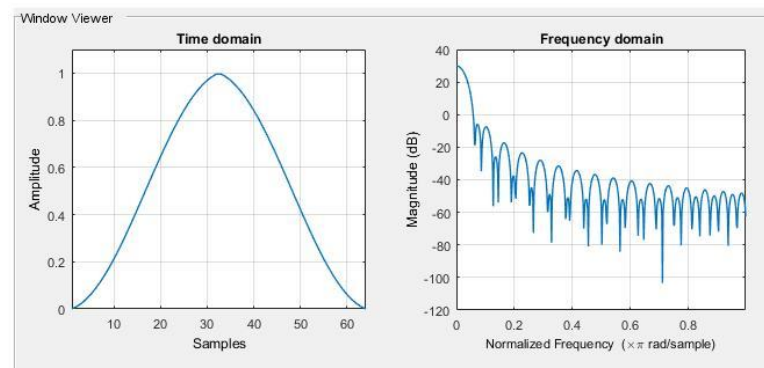

\section{Gambar 3. Modified Bartlett Hann window dalam domain waktu dan frekuensi.}

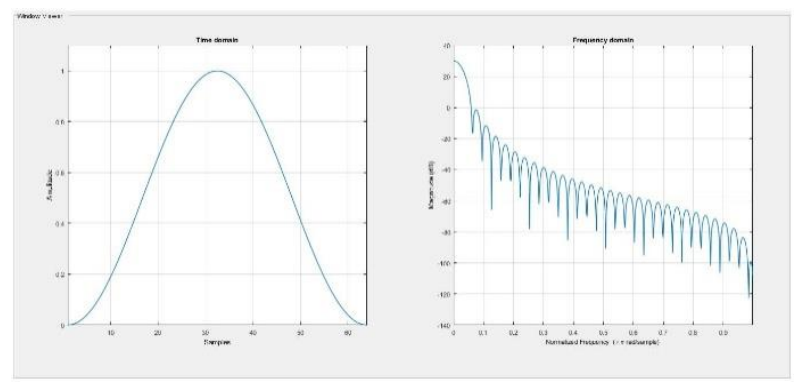

\section{Gambar 4. Blackman window dalam domain waktu dan frekuensi.}

Gambar 3 dan 4 menunjukkan batasan yang digunakan untuk mengcover data nada yang dihasilkan oleh pita suara dengan panjang windownya 40. Secara berurutan grafik pada Gambar 3 dan 4 diperoleh dari persamaan:

$w(n)=0.62-0.48\left|\left(\frac{n}{N}-0.5\right)\right|+$
$0.38 \cos \left(2 \pi\left(\frac{n}{2}-0.5\right)\right) \ldots \ldots \ldots \ldots \ldots . .(2)$

dan

$$
\begin{aligned}
& w(n)=0.42-0.5 \cos \frac{2 \pi n}{N-1}+ \\
& 0.08 \cos \frac{4 \pi n}{N-1}
\end{aligned}
$$

dimana $0 \leq n \leq M-1$ untuk Blackmann, $0 \leq n \leq N$ untuk modified Bartlett-Hanning window, jumlah sampel yang digunakan, dan $w(n)$ adalah window. Data suara yang dianalisis mengunakan algoritma DFT akan tersimpan didalam soundcard yang sudah 
terintergrasi dengan personal computer (PC).
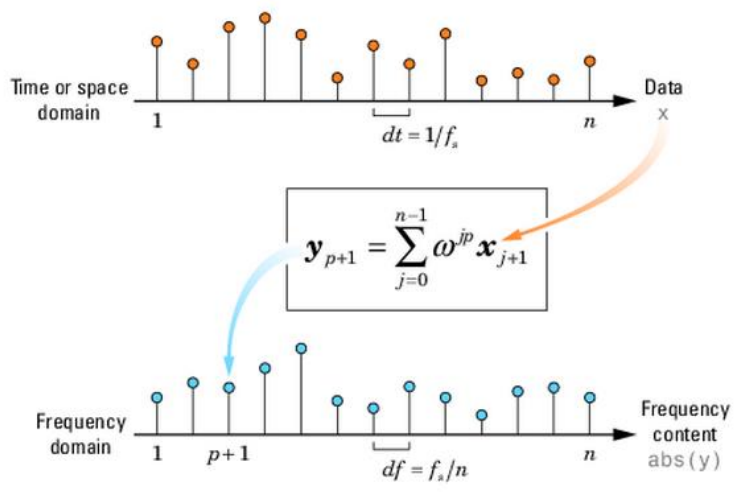

\section{Gambar 5. Ilustrasi transformasi dari} domain waktu ke frekuensi

Sound card merupakan bagian dari PC yang berfungsi untuk mengkonversi sinyal anolog menjadi sinyal digital (ADC), dan dapat mengkonversi sinyal digital menjadi analog (DAC).

\subsection{Metodologi Penelitian}

Suara yang dihasilkan oleh pita suara akan direkam dengan menggunakan microphone selama 5 detik, kemudian suara tersebut akan disimpan oleh soundcard yang terintegrasi dengan PC. Suara yang tersimpan dapat diakses, dan dioleh dengan mengunakan perangkat lunak matlab R2014a. Algoritma yang digunakan untuk mengolah data suara adalah discerete Fourier transform (DFT). Output dari algoritma tersebut adalah data suara dalam domain frekuensi. Alur dari proses ini terlihat di Gambar 6.

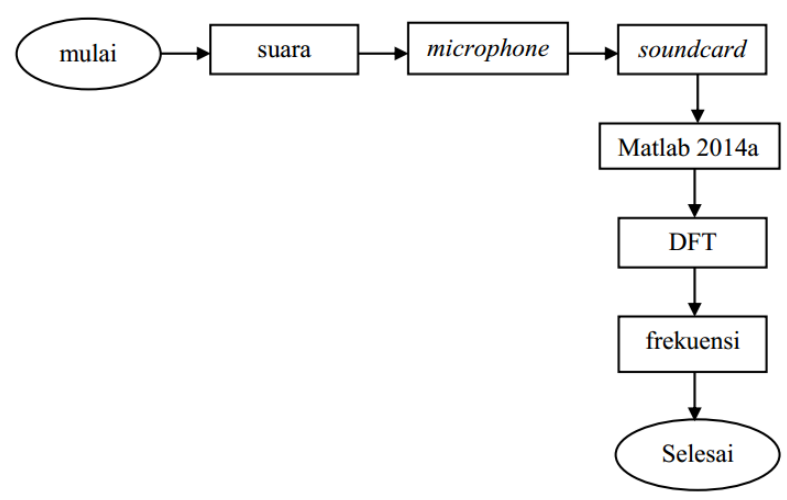

Gambar 6. Diagram alir penelian.
Sampel suara yang digunakan adalah suara orang dewasa. Sampel suara yang akan diambil harus terbebas dari noise, sehingga waktu pengambilan data dilaku-kan pada waktu yang tidak terdapat noise. Sampel suara berupa huruf vokal $\boldsymbol{a}, \boldsymbol{i}$, $\boldsymbol{u}$, dan $\boldsymbol{o}$

\subsection{Hasil dan Diskusi}

Frekuensi yang dari setiap pengucapan huruf vokal akan berberbeda sesuai dengan jenis huruf yang diucapkan sebagaimana tampak pada Gambar 7 \& 11 .
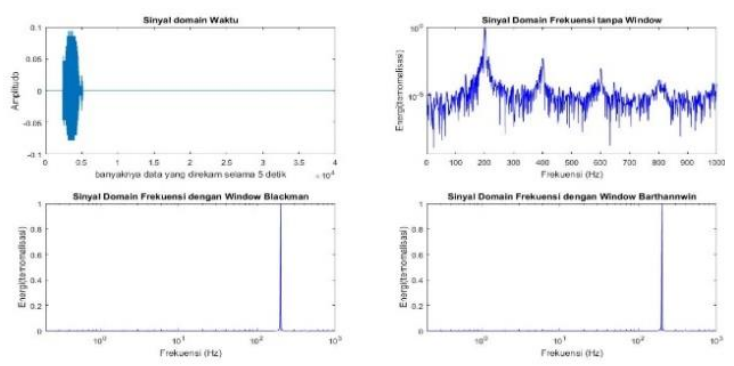

Gambar 7. Nada $i$ dalam domain waktu dan frekuensi.
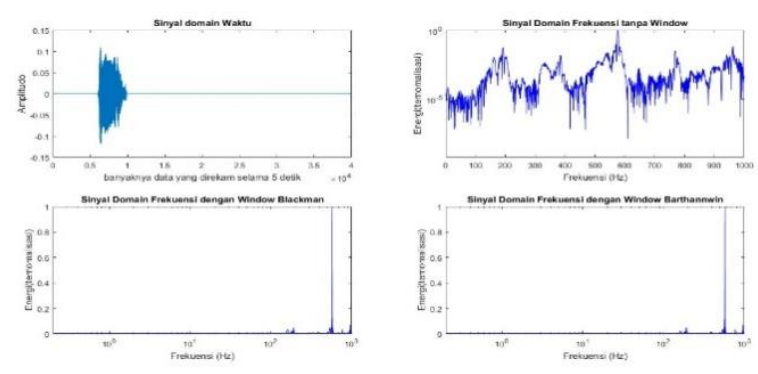

Gambar 8. Nada o dalam domain waktu dan frekuensi.
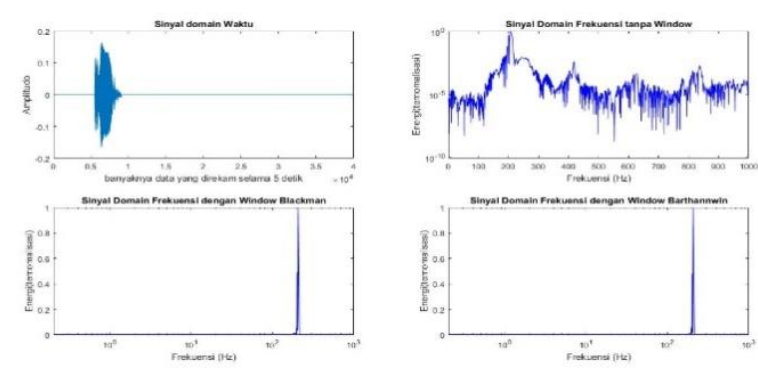

Gambar 9. Nada $u$ dalam domain waktu dan frekuensi. 

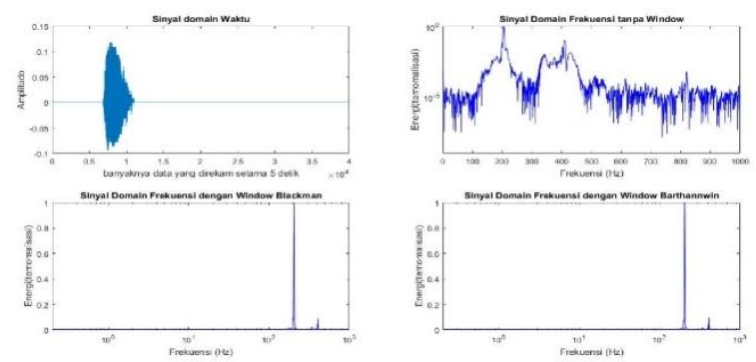

Gambar 10. Nada $e$ dalam domain waktu dan frekuensi.
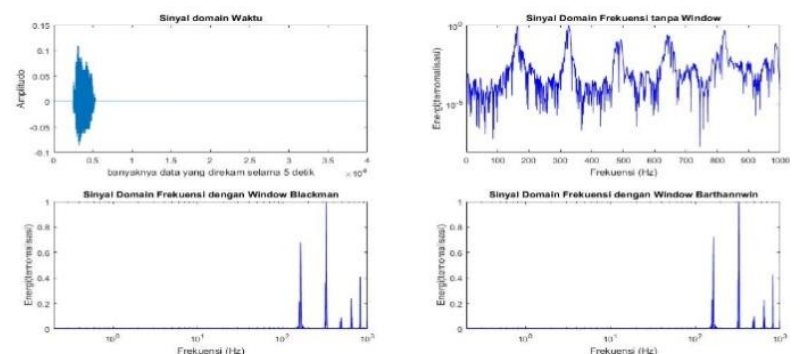

\section{Gambar 11.Nada $a$ dalam domain waktu dan frekuensi.}

Frekuensi yang dihasilkan oleh nada $\boldsymbol{i}$ adalah $190 \mathrm{~Hz}$ dengan amplitudo 0,14 dB, nada $\boldsymbol{o}$ adalah $580 \mathrm{~Hz}$ dengan amplitudo 0,1 $\mathrm{dB}$, nada $\boldsymbol{u}$ adalah $210 \mathrm{~Hz}$ dengan amplitudo $0,15 \mathrm{~dB}$, nada $\boldsymbol{e}$ adalah $200 \mathrm{~Hz}$ dengan amplitudo 0,13 dB, dan nada $\boldsymbol{a}$ adalah 310 $\mathrm{Hz}$ dengan $0,1 \mathrm{~dB}$.

Berdasarkan data, amplitudo yang dihasilkan bervariasi, dimana amplitudo nada $\boldsymbol{u}$ lebih besar daripada amplitudo nada $\boldsymbol{a}, \boldsymbol{i}, \boldsymbol{e}$, dan $\boldsymbol{o}$. Hal ini menyatakan bahwa pada saat mengeluarkan nada $\boldsymbol{u}$, Energi yang diperlukannya lebih besar dibadingkan dengan huruf-huruf vokal lainnya, dan ini terlihat pada energi ternomalisasi pada Gambar 9. Pada saat pita suara mengeluarkan nada akan terjadi gema/bagian pita yang bergetar. Peristiwa ini terlihat pada saat mengucapkan nada $\boldsymbol{a}$ sebaimana yang diperlihatkan oleh Gambar 11. Pada gambar tersebut terdapat 4 spike yang kecil. Spike ini menunjukkan getaran yang terjadi pada pita suara.

Walaupun pengambilan data diatur pada waktu yang tidak menimbulkan noise, noise terdeteksi pada saat pengambilan data sebagaimana diperlihatkan pada Gambar 12.
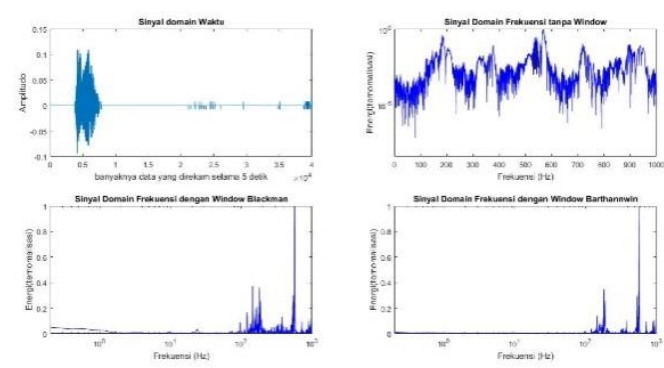

Gambar 12. Nada $o$ yang terdapat noise.

Gambar 12 juga menunjukkan adanya perbedaan pengurangan kebocoran window (window leakage) atau noise dengan menggunakan algoritma Black-mann dengan Barthannwin modified, dan noise yang dihasilkan berasal dari perangkat personal computer (PC). Hasil menunjukkan algoritma Barthannwin modified lebih baik dibandingkan dengan algoritma Blackmann. Hal ini disebabkan algoritma Barthannwin mempunyai window lebih kecil dibangkan dengan algoritma Blackmann, dan ini diperlihatkan oleh Gambar 4.

\section{Kesimpulan}

Berdasarkan uraian diatas, discerete Fourier transform dapat digunakan mengkarakterisasi nada dari huruf vokal $\boldsymbol{a}, \boldsymbol{i}, \boldsymbol{u}, \boldsymbol{e}$, dan $\boldsymbol{o}$. Frekuensi ,dan amplitudo yang dihasilkan oleh nada dari huruf vokal adalah nada $\boldsymbol{i}$ adalah $190 \mathrm{~Hz}$ dengan amplitudo 0,14 dB, nada $\boldsymbol{o}$ adalah $580 \mathrm{~Hz}$ dengan amplitudo $0,1 \mathrm{~dB}$, nada $\boldsymbol{u}$ adalah $210 \mathrm{~Hz}$ dengan amplitudo 0,15 dB, nada $\boldsymbol{e}$ adalah $200 \mathrm{~Hz}$ dengan amplitudo 0,13 dB, dan nada $\boldsymbol{a}$ adalah $310 \mathrm{~Hz}$ dengan 0,1 dB. Noise yang dihasilkan oleh nada $\boldsymbol{o}$ pada saat pengambilan data disebabkan oleh perangkat personal computer (PC).

\section{Daftar Pustaka}

Oppenheim, Alan V., Ronald W. Schafer, and John R. Buck. Discrete-Time Signal 
Processing. Upper Saddle River, NJ: Prentice Hall, 1999, pp. 468-471.

Estrada, Richie, 2008, Pengolahan Sinyal Suara menggunakan Matlab, Teknokrida.

Gerhard, David, 2003, Pitch Extraction and Faundamental Frequency: History and current Technique, Department and Computer Science, University of Regina, Canada.
Gilat, A. dan Subramaniam, 2013, Numerical methods for Engineering and Scientist $3^{\text {rd }}$ Edition, Wiley.

Niederwimmer, K., Kieberger, B., dan Hassel, A.W., 2015, Analysis of main failure pattern using discrete Fourier transform on metalepoxy-based adherent-laminates, 1242-1248, Physics Status Solidi. 